OPEN ACCESS

Edited by:

Guzide Aksu,

Ege University, Turkey

Reviewed by:

Li Fen Liu,

Stanford University, United States

Elham Hossny,

Ain Shams University, Egypt

Esther De Vries,

Tilburg University,

Netherlands

*Correspondence:

Aurora Daniele

aurora.daniele@unicampania.it

tThese authors have contributed equally to this work.

Specialty section:

This article was submitted to Primary Immunodeficiencies,

a section of the journal

Frontiers in Immunology

Received: 09 May 2017

Accepted: 13 July 2017

Published: 31 July 2017

Citation:

Pecoraro A, Nigro E, Polito R, Monaco ML, Scudiero O, Mormile I,

Cesoni Marcelli A, Capasso M,

Habetswallner F, Genovese A,

Daniele A and Spadaro G (2017)

Total and High Molecular Weight Adiponectin Expression Is Decreased

in Patients with Common Variable Immunodeficiency: Correlation with Ig Replacement Therapy.

Front. Immunol. 8:895.

doi: 10.3389/fimmu.2017.00895

\section{Total and High Molecular Weight Adiponectin Expression Is Decreased in Patients with Common Variable Immunodeficiency: Correlation with Ig Replacement Therapy}

\author{
Antonio Pecoraro ${ }^{1 t}$, Ersilia Nigro ${ }^{2,3 t}$, Rita Polito ${ }^{2,3}$, Maria Ludovica Monaco', \\ Olga Scudiero ${ }^{2,4}$, Ilaria Mormile', Azzurra Cesoni Marcelli', Mario Capasso ${ }^{2,4}$, \\ Francesco Habetswallner ${ }^{4}$, Arturo Genovese ${ }^{1}$, Aurora Daniele ${ }^{2,3 *}$ and Giuseppe Spadaro ${ }^{1}$ \\ ${ }^{1}$ Department of Translational Medical Sciences, Allergy and Clinical Immunology, University of Naples Federico II, Naples, \\ Italy, ${ }^{2}$ CEINGE-Biotecnologie Avanzate Scarl, Napoli, Italy, ${ }^{3}$ Dipartimento di Scienze e Tecnologie Ambientali Biologiche \\ Farmaceutiche, Università degli Studi della Campania "Luigi Vanvitelli", Caserta, Italy, ${ }^{4}$ Dipartimento di Medicina Molecolare e \\ Biotecnologie Mediche, Università di Napoli Federico II, Napoli, Italy
}

Adiponectin (Acrp30) is an adipokine widely studied for its beneficial metabolic properties. It circulates as low molecular weight (LMW), medium molecular weight (MMW), and high molecular weight (HMW) oligomers. The latter exerts the most potent biological effects. Acrp30 attracted renewed interest with the finding that it was associated with the development and progression of immune disorders. The mechanisms underlying this association and the role of Acrp30 in the pathophysiology of immune-mediated conditions remain unknown. Common variable immunodeficiency (CVID) is a primary immunodeficiency characterized by chronic activation of the immune system, impaired antibody production, and imbalanced cytokine production. In the attempt to shed light on the expression of Acrp30 in CVID, we: (a) investigated total Acrp30 and its oligomerization state in CVID patients undergoing maintenance Ig replacement therapy; (b) assessed the effects of Ig replacement therapy on Acrp30 expression in treatment-naïve CVID patients, namely, patients not treated before diagnosis, before and after the first Ig administration; and (c) evaluated the correlation between Acrp30 levels and clinical phenotypes of the disease. As controls, we analyzed healthy subjects and patients affected by a non-immunodeficiency chronic inflammatory demyelinating polyneuropathy (CIDP), before and after lg infusion. We found that total Acrp30 and HMW oligomers were decreased in CVID but not in CIDP patients versus controls. Moreover, Acrp30 levels were correlated with IgA levels and were associated with two CVID phenotypes, namely, autoimmune cytopenia and enteropathy. Receiver operating characteristic curve analysis indicated that Acrp30 modulation is specific for CVID patients. Acrp30 and HMW levels quickly and dramatically increased after lg infusion only in eight treatment-naiive CVID patients but not in five CIDP patients. This finding indicates that Ig administration per se is not able to induce an increase of Acrp30, but the specific cellular and/or molecular background proper of CVID seems to be essential. In conclusion, our data indicate that Acrp30 is specifically related to CVID activity. Further studies are required to understand the biological role of Acrp30 and its possible use as disease biomarker in CVID.

Keywords: common variable immunodeficiency, adiponectin, high molecular weight oligomers, immunoglobulin, adipose tissue, intravenous immunoglobulin, immunoglobulin replacement therapy 


\section{INTRODUCTION}

Common variable immunodeficiency (CVID) is a primary immunodeficiency characterized by reduced serum levels of IgG, $\operatorname{IgA}$, and/or IgM, which results in impaired antibody production. CVID is one of the most frequent primary immunodeficiencies in adults and its prevalence ranges from 1:10,000 to 1:50,000 (1). It is generally diagnosed between the ages of 20 and 40 years (1). CVID patients can be divided into four clinical phenotypes: (1) no CVID-related complications besides infections; (2) cytopenias (thrombocytopenia, autoimmune hemolytic anemia or neutropenia); (3) polyclonal lymphoproliferation (granuloma, lymphocytic interstitial pneumonia, persistent unexplained lymphadenopathy); and (4) unexplained persistent enteropathy (2-4). An altered cytokine profile and abnormalities in immune cellular subpopulations consistent with a substantial chronic inflammatory condition have been reported in CVID patients $(5,6)$; however, the mechanisms underlying the chronic immune activation associated with CVID remain largely obscure.

Beyond the well-known impairment of B cell function, the spectrum of cytokines upregulated in CVID patients seems to reflect ongoing activation of several myeloid cells mainly monocytes, macrophages, and neutrophils $(5,6)$. White adipose tissue is an important site for the establishment of inflammation consequent to secretion of the biologically active mediators, adipokines (7-10). One of these, namely adiponectin (Acrp30), circulates in serum as complexes of different molecular weight: low molecular weight (LMW), medium molecular weight (MMW), and high molecular weight (HMW) $(11,12)$. Interestingly, HMW Acrp30 oligomers elicit more potent biological effects than do the other two oligomers (12). Acrp30 expression is low in such metabolic disorders as obesity, type 2 diabetes mellitus, and obstructive sleep apnea syndrome (13-16). In patients affected by these diseases, Acrp30 is often negatively associated with the inflammatory markers tumor necrosis factor $\alpha(\mathrm{TNF}-\alpha)$, interleukin 6 (IL-6), and $\mathrm{C}$ reactive protein. Conversely, Acrp30 is overexpressed in autoimmune diseases, mainly rheumatoid arthritis and systemic lupus erythematosus, and in chronic obstructive pulmonary disease, which are diseases characterized by a chronic inflammatory status $(1,17)$. Neither the causes of Acrp30 upregulation nor the role it plays in these disorders is known. In addition, Acrp30 receptors are expressed on the surface of peripheral blood mononuclear cells, which is consistent with functional immunomodulatory signaling (18-21). Acrp30 is also an important regulator of macrophage proliferation, plasticity, and function in inflammation

Abbreviations: Acrp30, adiponectin; APN-KO, adiponectin knockout; BMI, body mass index; COPD, chronic obstructive pulmonary disease; CRP, $\mathrm{C}$ reactive protein; CVID, common variable immunodeficiency; ELISA, enzyme-linked immunosorbent assay; FPLC, fast protein liquid chromatography; HMW, high molecular weight; Ig, immunoglobulin; IgA, immunoglobulin A; IgG, immunoglobulin G; IL-6, interleukin 6; IVIG, intravenous immunoglobulin; LMW, low molecular weight; MMW, medium molecular weight; NF- $\kappa$, nuclear factor kappa-light-chain-enhancer of activated B cells; OSAS, obstruction sleep apnea syndrome; PBMCs, peripheral blood mononuclear cells; ROC, receiver operating characteristic; SDS-PAGE, sodium dodecyl sulfate-polyacrylamide gel electrophoresis; TNF- $\alpha$, tumor necrosis factor $\alpha$. and its related metabolic disorders (22-24). Acrp30 inhibits the growth of myelomonocytic progenitors (22) and downregulates the inflammatory responses involving TNF- $\alpha$ (10, 25-29). In addition, Acrp30 oligomers may exert different functions, for example HMW, but not LMW. Acrp30 enhances IL-6 production in primary human monocytes $(30,31)$. Some adipokines including leptin, were recently found to be differentially modulated in CVID patients versus control subjects $(30,32-35)$.

The aims of the present study were to: (i) analyze Acrp30 expression levels and its oligomerization state in a large cohort of CVID patients in maintenance Ig replacement therapy; (ii) determine whether Acrp30 fluctuations are related to different clinical phenotypes; (iii) investigate the role of Acrp30 in immunodeficiency by monitoring the levels of this adipokine in eight treatment-naïve CVID patients (i.e., patients not treated before diagnosis) before and after the first Ig replacement therapy administration versus. As controls, we measured Acrp30 levels in healthy subjects and in patients affected by chronic inflammatory demyelinating polyneuropathy (CIDP) before and after Ig infusion therapy versus five CIPD patients before and after Ig infusion.

\section{MATERIALS AND METHODS}

\section{Recruitment of Subjects}

We recruited 52 patients in maintenance treatment with Ig (28 men, 24 women) and 8 ( 4 men and 4 women) treatmentnaïve patients at the time of CVD diagnosis based on the 2014 European Society for Immunodeficiencies diagnostic criteria of 2014, from the Division of Allergy and Clinical Immunology of the Department of Translational Medical Sciences, University of Naples Federico II. In addition, we recruited five patients (three men, two women) with a diagnosis of CIDP from the Azienda Ospedaliera A. Cardarelli.

From the medical files of CVID patients, we recorded serum Ig levels, T cell count, and B cell subsets at diagnosis, clinical history of recurrent infections, chronic diarrhea, bronchiectasis, autoimmune diseases (autoimmune hemolytic anemia, immune thrombocytopenia, neutropenia), polyclonal lymphoproliferation (splenomegaly, lymphadenopathy, and granulomatous disease), and malignancies.

Common variable immunodeficiency patients received continuous Ig replacement therapy (36 patients received IgVena ${ }^{\circledR} /$ Kedrion, 6 patients Flebogamma ${ }^{\circledR} /$ Grifols, 5 patients Kiovig ${ }^{\circledR} /$ Baxalta, 2 patients Gammagard ${ }^{\circledR} /$ Baxalta, 2 patients Octagam $^{\circledR} /$ Octapharma, and 1 patient Privigen ${ }^{\circledR} /$ Behring) $(0.4 \mathrm{~g} / \mathrm{kg} / \mathrm{month})$ at intervals of 3 weeks to maintain IgG trough levels above $600 \mathrm{mg} / \mathrm{dl}(768 \pm 87 \mathrm{mg} / \mathrm{dl})$. There were no familial cases in the control group or among CVID patients. Treatment-naïve patients received intravenous Ig immunomodulating therapy (IgVena ${ }^{\circledR}$ $50 \mathrm{mg} / \mathrm{ml}$ by Kedrion S.p.A. at the dose of $0.4 \mathrm{~g} / \mathrm{kg} / 21$ days). Five patients with CIDP receiving intravenous immunoglobulin (IVIG) immunomodulating therapy (IgVena ${ }^{\circledR} 50 \mathrm{mg} / \mathrm{ml}$ by Kedrion S.p.A. at the dose of $0.4 \mathrm{~g} / \mathrm{kg} /$ day for 5 consecutive days) were collected. All CIDP patients had previously received IVIG immunomodulating therapy. Purity at $99 \%$ of Ig for the replacement therapy was guaranteed by Kedrion S.p.A. Fifty-four 
healthy volunteers from the CEINGE staff (27 men, 27 women), age-, body weight- and body mass index (BMI)-matched with the 52 CVID patients served as control group.

The research protocol was approved by the Ethics Committee of the School of Medicine, University of Naples "Federico II" and was conducted in accordance with the principles of the Helsinki II Declaration. Written informed consent was obtained from all participants.

\section{Anthropometric and Metabolic Measurements}

The height and weight of patients were measured using standard techniques and the BMI was calculated as body weight $(\mathrm{kg}) /$ height ${ }^{2}\left(\mathrm{~m}^{2}\right)$. Samples of serum were collected from all patients and from the eight treatment-naïve patients before the first Ig replacement administration $(0.4 \mathrm{~g} / \mathrm{kg})$ and $24 \mathrm{~h}, 7$ days, 14 days, and 21 days thereafter. Serum samples were collected from patients with CIDP before Ig therapy and $24 \mathrm{~h}$ and 7 days thereafter $(0.4 \mathrm{~g} / \mathrm{kg})$. Biochemical measurements are reported in Table S1 in Supplementary Material. We verified the purity of the preparation by sodium dodecyl sulfate-polyacrylamide gel electrophoresis (SDS-PAGE) analysis stained with Coomassie brilliant blue and by ensuring the absence of Acrp30 in Ig solutions through western blotting with two Acrp30 antibodies (Custom antibody; PRIMM, Milan, Italy; Cell Signaling Technology, MA) (data not shown). Biochemical measurements are reported in Table 1 and Table S1 in Supplementary Material. Total Acrp30 was measured by enzyme-linked immunosorbent assay (ELISA) method as previously reported (32).

\section{Western Blot Analysis}

Five micrograms of serum total proteins were processed as previously described (15). All samples were tested twice in duplicate. Acrp30 antibody incubation was performed as previously described (36). Blots were developed by enhanced chemiluminescence (Amersham Bio-sciences) with Kodak BioMax Light film, digitalized with a scanner (1,200 dpi) and analyzed by densitometry with the ImageJ software (http://rsbweb.nih. gov.ij/). All experiments were performed in triplicate.

\section{Gel Filtration Analysis}

We analyzed the distribution of Acrp30 oligomers in serum by fast protein liquid chromatography (FPLC) on a Superdex 200 10/300 GL column connected to a FPLC system (Amersham Pharmacia Biotech, Sweden). In detail, $1.875 \mathrm{mg}$ of total proteins was fractionated at $0.5 \mathrm{ml} / \mathrm{min}$ using phosphate-buffered saline elution buffer. Fractions $(500 \mu \mathrm{l})$ were collected and Acrp30 was tested using ELISA $(70 \mu \mathrm{l})$ and western blotting $(20 \mu \mathrm{l})$ assays. The column was calibrated using ferritin $(440 \mathrm{kDa})$, aldolase (158 kDa), and ovalbumin (44 kDa) (GE Healthcare).

\section{Statistical Analysis}

Data are expressed as means \pm SD and median. The significances of biochemical parameters differences were determined using the Mann-Whitney test. The chi-square test was used to compare sex ratio. A multiple logistic regression analysis was performed to correct the significant $p$-values of the univariate analysis. We performed a receiver operating characteristic curve (ROC) analysis to determine whether Acrp30 levels are specifically modulated in CVID and the optimum cutoff point. The one-way repeated measures analysis of variance with Greenhouse-Geisser corrections was used to examine the association among biochemical parameters, Acrp30, and IgG levels after replacement therapy. Pairwise comparisons were performed using Fisher's Least Significant Difference method. The statistical significance was established at $p<0.05$.

\section{RESULTS}

\section{Anthropometric and Biochemical Features}

As shown in Table 1, the levels of total cholesterol $(p<0.015)$, total proteins $(p<0.0001)$, and iron $(p<0.0001)$ were lower in CVID patients than in controls. Both SDS-PAGE and western blotting analysis revealed the absence of Acrp30 in Ig solutions.

TABLE 1 | Clinical and biochemical features of common variable immunodeficiency (CVID) patients and controls.

\begin{tabular}{|c|c|c|c|c|c|c|c|}
\hline Parameters & CVID patients $N=52$ & Mean & SD & Controls $N=54$ & Mean & SD & $p$-Value \\
\hline Sex male/female & $28 / 24$ & - & - & $27 / 27$ & - & - & 0.69 \\
\hline Age (years) & 52 & 48.7 & 16.9 & 54 & 49.3 & 16.3 & 0.704 \\
\hline Weight (kg) & 52 & 68.0 & 14.6 & 51 & 69.5 & 12.7 & 0.345 \\
\hline Body mass index $\left(\mathrm{kg} / \mathrm{m}^{2}\right)$ & 52 & 24.7 & 4.0 & 54 & 23.9 & 3.2 & 0.383 \\
\hline Total cholesterol (mg/dl) & 52 & 173.3 & 39.8 & 50 & 197.4 & 45.9 & 0.015 \\
\hline Tryglicerides (mg/dl) & 52 & 103.6 & 44.3 & 51 & 99.0 & 46.6 & 0.413 \\
\hline Glycemia (mg/dl) & 52 & 82.7 & 19.5 & 54 & 89.0 & 11.5 & \\
\hline $\lg G(\mathrm{mg} / \mathrm{dl})$ & 52 & 227.7 & 126.4 & 0 & - & - & - \\
\hline $\lg A(m g / d l)$ & 52 & 9.1 & 13.4 & 0 & - & - & - \\
\hline $\operatorname{lgM}(\mathrm{mg} / \mathrm{dl})$ & 52 & 22.7 & 48.5 & 0 & - & - & - \\
\hline Total proteins (g/dl) & 52 & 6.6 & 0.5 & 33 & 7.5 & 0.5 & $<0.0001$ \\
\hline Alpha2 (\%) & 52 & 11.7 & 2.1 & 0 & - & - & - \\
\hline Iron ( $\mu \mathrm{g} / \mathrm{dl})$ & 52 & 64.4 & 29.8 & 36 & 96.3 & 42.0 & $<0.0001$ \\
\hline Ferritin (ng/ml) & 52 & 127.1 & 176.9 & 15 & 110.8 & 69.5 & 0.412 \\
\hline Fibrinogen (mg/dl) & 51 & 355.4 & 91.0 & 0 & - & - & - \\
\hline C reactive protein $(\mathrm{mg} / \mathrm{dl})$ & 51 & 0.6 & 0.6 & 11 & 0.4 & 0.1 & 1 \\
\hline ESR (mm) & 52 & 12.8 & 10.7 & 11 & 11.2 & 8.2 & 0.913 \\
\hline
\end{tabular}

Statistically relevant values are reported in bold. 
Furthermore, cross-reactivity between Acrp30 antibodies and Ig was excluded by testing two different concentrations of Ig (6 and $8 \mathrm{mg} / \mathrm{ml}$ ) in ELISA, whereas the level of Acrp30 was significantly lower in controls than in CVID patients $(17 \pm 0.4$ versus $27 \pm 0.7 \mu \mathrm{g} /$ $\mathrm{ml} ; p<0.0001$ ) (Figure 1A). After correcting for iron and cholesterol covariates, total Acrp30 levels remained significantly lower in CVID patients $(p<0.0001)$. Moreover, Acrp30 levels were higher in the subgroup of patients with an IgA level at diagnosis $>7 \mathrm{mg} / \mathrm{dl}$ than in those with an IgA level at diagnosis $\leq 7 \mathrm{mg} / \mathrm{dl}$ $(1.8 \pm 0.3$ versus $1.6 \pm 0.3 \mu \mathrm{g} / \mathrm{ml} ; p=0.03)$ (Figure 1B).

\section{Acrp30 Expression in CVID Patients Compared to Controls}

We performed a ROC curve analysis to verify if Acrp30 level could be an independent discriminative value to predict CVID (Figure 1C). The comparison between 54 controls and 52 CVID patients demonstrated that a cutoff value of $13.7 \mu \mathrm{g} / \mathrm{ml}$ Acrp30 corresponded to a sensitivity of $100 \%$ and a specificity of $81 \%$ $\left(\mathrm{AUC}=0.947, p=2.28 \times 10^{-15}\right)$. Using this cutoff point, Acrp30 levels were significantly lower in the "autoimmune cytopenias" and "enteropathy" subsets than in the controls, whereas no differences versus controls were found in the "polyclonal lymphoproliferation" and "recurrent infections" subsets (Figure 1D).

\section{Western Blotting and FPLC Analysis of Acrp30 Oligomerization State}

Figure 2 shows the distribution of serum Acrp30 in control subjects and in CVID patients. After WB analysis performed on serum, three bands corresponding to HMW ( $\geq 250 \mathrm{kDa}), \mathrm{MMW}$ $(\geq 180 \mathrm{kDa})$, and $\mathrm{LMW}(\geq 70 \mathrm{kDa})$ oligomers were identified in both controls and CVID patients (Figure 2A). As shown in Figure 2B, the expression of the HMW oligomers was significantly lower in CVID patients than in controls $(p<0.05)$. We also examined the distribution of Acrp30 oligomers by FPLC under native conditions. Both ELISA analysis (Figure 2C) and western blotting (Figure 2D) confirmed that Acrp30 levels are lower in CVID patients than in controls. Notably, HMW were the oligomers predominantly reduced.

\section{Total Acrp30 and HMW Oligomer Levels Were Significantly Higher after IVIG Replacement Therapy in Treatment-Naïve CVID Patients but Not in CIPD Patients}

To investigate whether Acrp30 levels are related to Ig replacement therapy, we measured Acrp30 levels in eight treatment-naïve CVID patients before and after the first Ig replacement therapy,
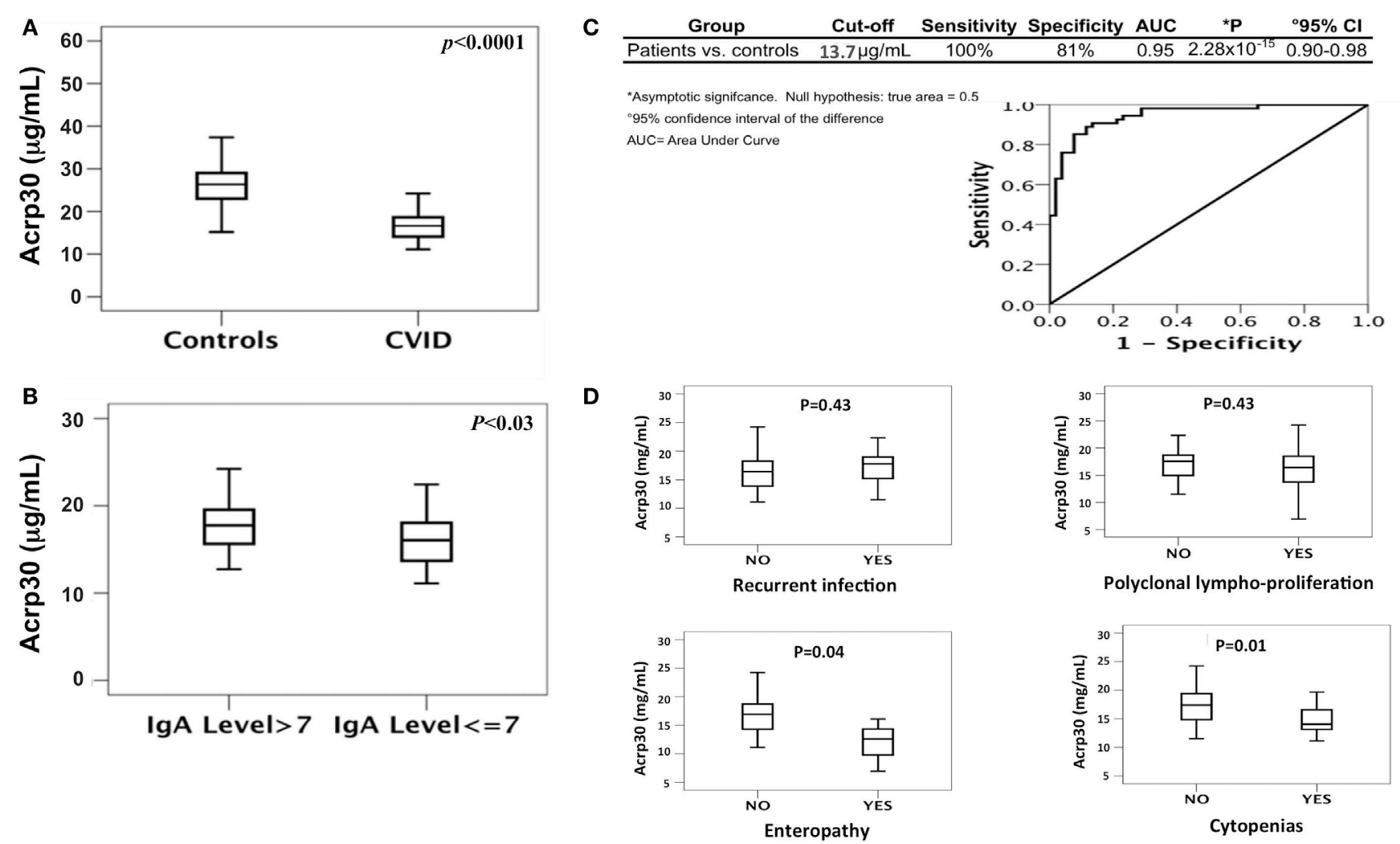

FIGURE 1 | Total adiponectin (Acrp30) levels are reduced in common variable immunodeficiency (CVID) patients compared to controls. (A) Box plots of Acrp30 serum levels in 52 CVID patients compared to 54 controls. (B) Box plots of Acrp30 serum levels in 52 CVID patients stratified according to lgA levels (7 g/l > lgA > 7 g/l). (C) Receiver operating characteristic curves of Acrp30 serum levels: values of CVID patients, controls, and graphical representation of CVID patients compared to controls. (D) Box plots of Acrp30 serum levels in CVID patients stratified according to clinical variables (recurrent infections, polyclonal lymphoproliferation, enteropathy, and cytopenias). For other details, see Section "Materials and Methods." 


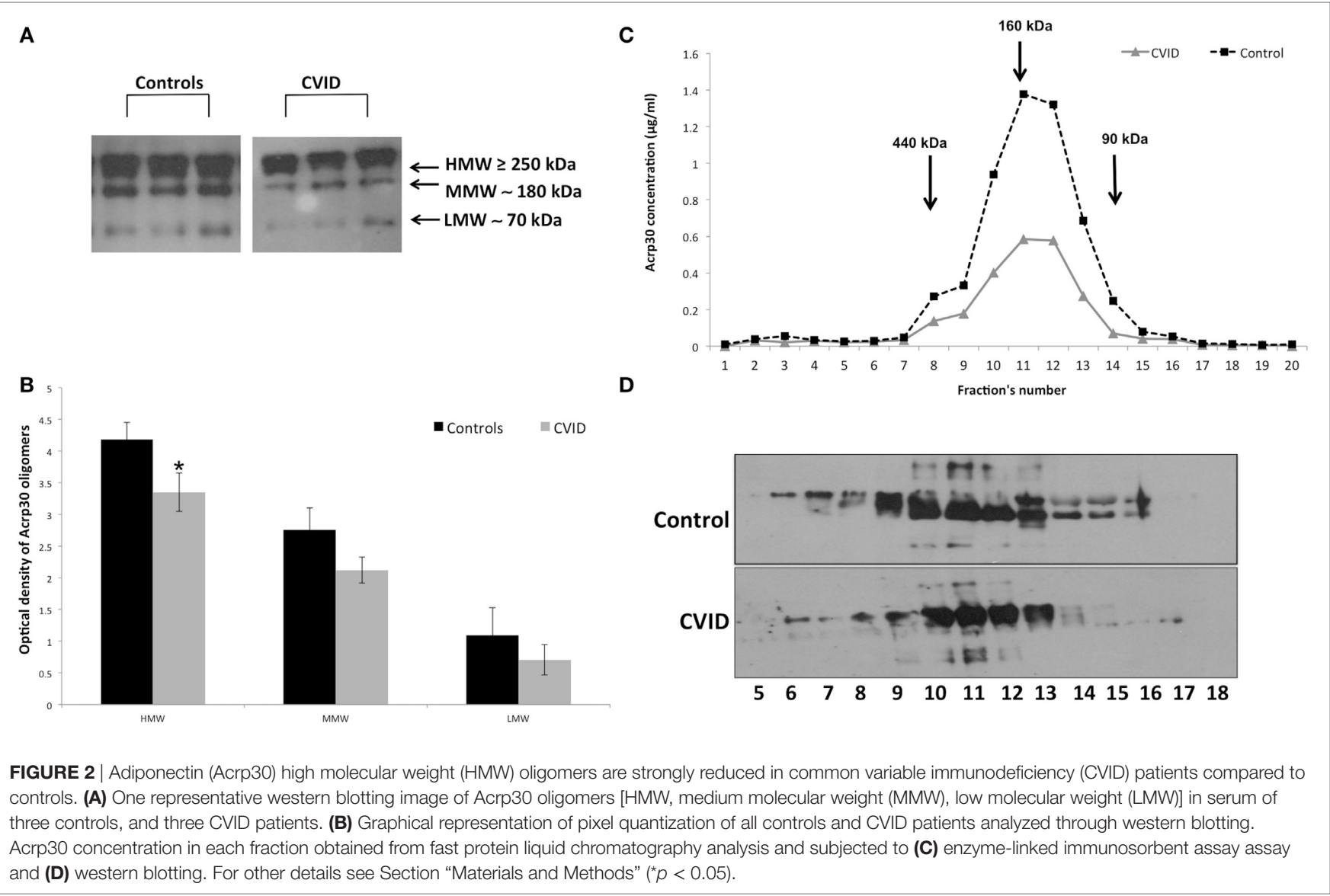

TABLE 2 | Adiponectin (Acrp30) levels strongly increase in common variable immunodeficiency (CVID) naïve patients but not patients with CIDP after lg replacement therapy.

\begin{tabular}{|c|c|c|c|c|c|c|}
\hline Parameters & \multicolumn{4}{|c|}{ Time (days) } & 21 & $p$-Value \\
\hline Acrp30 in CVID naïve patients ( $\mu \mathrm{g} / \mathrm{ml})$ & $10.96 \pm 7.63$ & $23.11 \pm 6.82$ & $21.82 \pm 3.56$ & $20.14 \pm 2.65$ & $17.65 \pm 4.34$ & 0.003 \\
\hline IgG in CVID naiive patients ( $g / l)$ & $2.79 \pm 1.98$ & $8.79 \pm 2.02$ & $6.50 \pm 1.65$ & $6.49 \pm 1.89$ & $5.37 \pm 2.32$ & 0.000003 \\
\hline Acrp30 $(\mu \mathrm{g} / \mathrm{ml})$ in CIDP & $15.28 \pm 1.48$ & $17.27 \pm 0.32$ & $17.28 \pm 0.29$ & nd & nd & $>0.05$ \\
\hline $\lg G(g / l)$ in CIDP & $11.75 \pm 1.94$ & $23.66 \pm 2.36$ & $17.705 \pm 4.21$ & nd & nd & 0.004 \\
\hline
\end{tabular}

Data given are mean \pm SD of eight CVID naive patients and five patients with chronic inflammatory demyelinating polyneuropathy (CIDP).

p-Value is obtained by one-way repeated measures analysis of variance with Greenhouse-Geisser corrections.

i.e., at $0,1,7,14$, and 21 days. Interestingly, Acrp30 levels were greatly increased already $24 \mathrm{~h}(208 \% \pm 7.45)$ after Ig infusion in all patients and remained high up to 21 days posttreatment and declined thereafter. Table 2 shows the relationship between Acrp30 and IgG levels, pre- and post-replacement therapy in eight treatment-naïve patients. A one-way repeated measures analysis of variance with Greenhouse-Geisser corrections showed that Acrp30 and IgG levels were significantly associated with the treatment at five time points $(p=0.003$ and $p=0.000003)$. The mean difference in Acrp30, IgA, and IgG levels between time 0 and the other time points was high but not significant, probably due the low number of patients (Table 2).

To verify if the Acrp30 increase is a specific characteristic of CVID patients subjected to Ig replacement therapy, we evaluated its levels before, and $24 \mathrm{~h}$ and 7 days after Ig immunomodulating therapy in CIDP patients, and found that the total Acrp30 level did not change (see Table 2). The specificity of the Acrp30 response to Ig administration is guaranteed by the high level of purity (>99\%) of the Ig solution injected in patients. We excluded Acrp30 contamination in Ig preparation by SDSPAGE and Coomassie coloration or western blot analysis (data not shown).

Furthermore, cross-reactivity between Acrp30 antibodies and Ig in ELISA was excluded by testing as controls two different concentrations of $\mathrm{Ig}(6$ and $8 \mathrm{mg} / \mathrm{ml})$. Each serum sample was tested four times in triplicate.

Table S1 in Supplementary Material shows the biochemical and anthropometrical parameters of 4 males and four females 
treatment-naïve patients. Ig administration strongly increased Acrp30 levels as early as $24 \mathrm{~h}$ after infusion in both patients, and remained high up to 14 days posttreatment; they were slightly decreased 21 days after treatment (Figure 3, upper panel). As expected, IgG levels were very high $24 \mathrm{~h}$ after treatment and remained high up to 21 days.

\section{DISCUSSION}

The molecular mechanism underlying the clinical manifestations of CVID has not yet been completely elucidated. However, chronic activation of the immune system in CVID patients is accompanied by dysregulation of various inflammatory cytokines (37-39), and an intricate adipokine-related network links adipose tissue to the immune system (34). In the attempt to shed light on Acrp30 in the adipokine-related network in CVID, we characterized the expression of Acrp30 and HMW oligomers, the most active forms, in patients undergoing maintenance Ig replacement therapy as well as in treatment-naïve CVID patients $(11,15,32)$. We found that the levels of Acrp30 and its HMW oligomers were lower in CVID patients than in age- and sex-matched controls, and that they correlate with IgA levels in these patients. Acrp30 levels were significantlylower in the subset of CVID patients with IgA levels at diagnosis $\leq 7 \mathrm{mg} / \mathrm{dl}$ than in

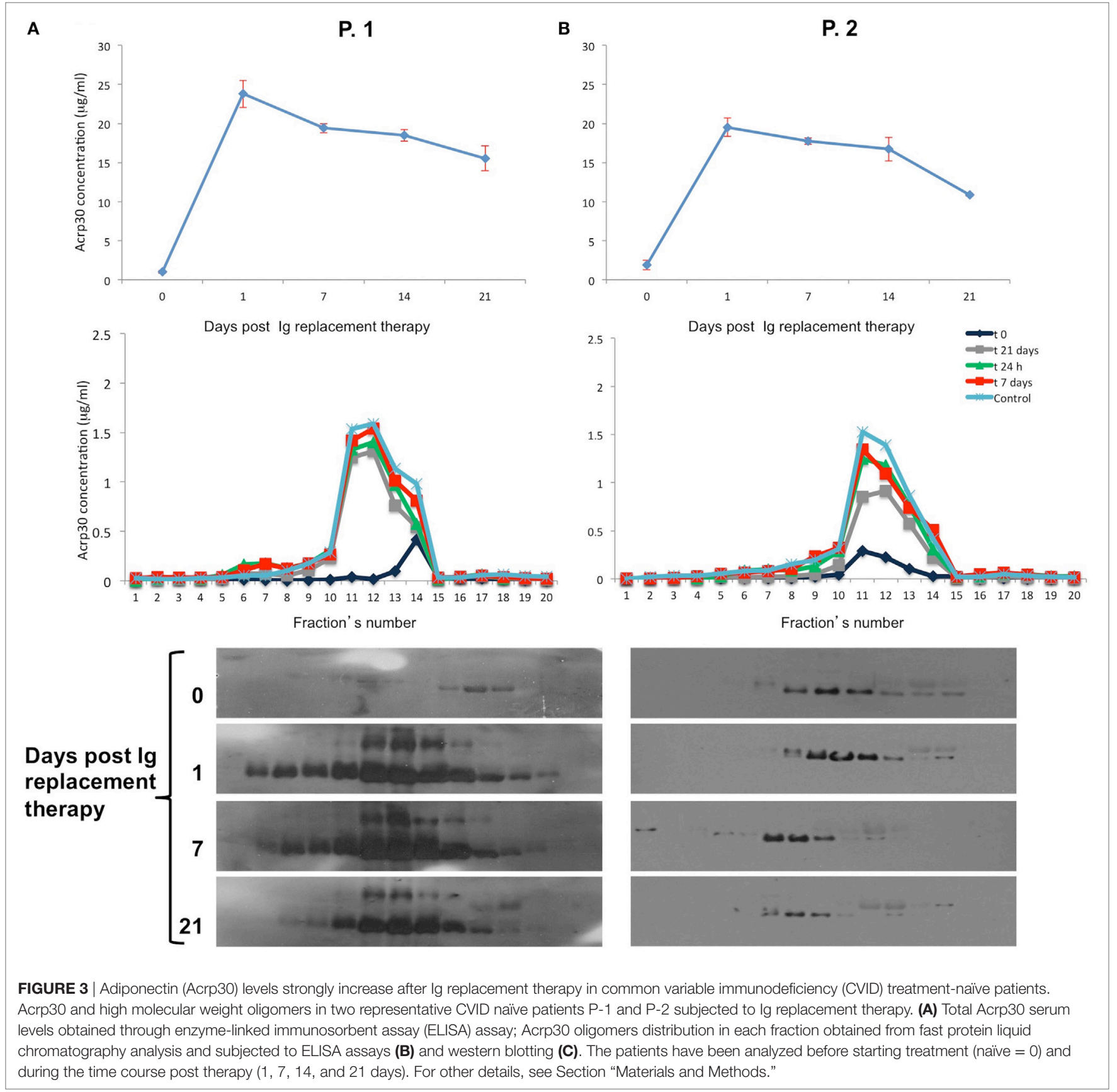


those with IgA levels at diagnosis $>7 \mathrm{mg} / \mathrm{dl}$, which confirms the strict correlation between adipose tissue and the immune system. Quinti et al. reported that IgA levels at diagnosis $<7 \mathrm{mg} / \mathrm{dl}$ define a subgroup of patients at a higher risk for pneumonia and, consequently, a poor prognosis (40). Similarly, we show that a late diagnosis is associated with a worst prognosis in CVID patients with IgA serum levels below $7 \mathrm{mg} / \mathrm{dl}$ (41). In this scenario, the very low serum expression of Acrp30 in patients with the most CVID severe phenotypes suggests that this adipokine could be associated to some clinical manifestations of CVID and could thus be considered a potential marker of the severity and prognosis of this disease.

In the light of this evidence, we investigated the effects of Ig replacement on Acrp30 expression in treatment-naïve CVID patients before and after the first Ig administration. Interestingly, in these patients, Ig replacement therapy rapidly induced an increase of Acrp30, which was associated with IgG levels. On the contrary, Acrp30 levels did not change after Ig replacement therapy in patients affected with a non-immunodeficiency syndrome, namely, CIDP, which indicates that Acrp30 plays a role in CVID. One-way repeated analysis showed a direct relationship between Acrp30 and IgG levels $(p=0.09$ and $p=0.087)$ at two time points in the treatment-naive patients thereby confirming the specificity of the relationship between the increase in Acrp30 and Ig administration.

Our data suggest that adipose tissue functions as an endocrine organ and participates in the immune response. In addition, our analysis of CIPD patients confirmed the specificity of Acrp30 expression in response to Ig therapy in CVID patients. In fact, Acrp30 levels did not increase in these patients after the administration of either $0.4 \mathrm{~g} / \mathrm{kg}$ of $\mathrm{Ig}$ ( $24 \mathrm{~h}$ posttreatment) or $2 \mathrm{~g} / \mathrm{kg}$ of Ig (7 days posttreatment). These findings indicate that Ig administration per se is not able to induce the increase of Acrp30, but it seems that the specific cellular and/or molecular background of CVID is required to modulate Acrp30 levels. However, a limitation of our study is the relatively low number of CIDP patients. Since our treatment-naïve CVID patients were characterized by low Acrp30 concentrations (Table 2), we hypothesize that Ig administration modulates the activation state and the cytokine profile involved in the chronic immune activation signature of CVID. Therefore, the increase of Acrp30 levels observed in treatment-naive CVID patients could be related to the change in the cytokine milieu induced by Ig administration. In this context, it is noteworthy that Ig, greatly reduced the expression of the pro-inflammatory IL-1b and IL- 6 cytokines in adipocytes $(42,43)$.

We also found an association between Acrp30 and autoimmune cytopenias/enteropathy phenotypes in the CVID cohort. In detail, Acrp30 levels were significantly lower in patients with autoimmune cytopenias/enteropathies than in patients with other phenotypes. This finding is relevant considering that about $10-20 \%$ of CVID patients suffer from autoimmune cytopenias (2, 44-47) and 10\% from enteropathy (2). Moreover, CVID patients without infectious complications have a poorer prognosis than the "infections only" subset, and have an 11-fold higher risk of death (40). On the other hand, CVID patients with enteropathies very often have a local or systemic inflammatory state characterized by elevated levels of pro-inflammatory cytokines that could contribute to the decrease of Acrp30 levels (48). Thus, the dysregulation of Acrp30 expression we observed could be related to the biological mechanisms in which this adipokine is involved, i.e. inflammatory processes and immune cell regulation (49). On the other hand, dysregulated Acrp30 levels have been found in such immune disorders as rheumatoid arthritis (50), systemic lupus erythematosus (51), and inflammatory bowel disease (52). Whether Acrp30 is an anti- or pro-inflammatory factor remains to be established, even though the prevailing notion is that it is a pro-inflammatory molecule $(31,53,54)$. Consistent with this concept, adiponectin knockout mice display increased M1 markers and decreased M2 markers (55-57). Notably, Acrp30, by reducing T cell transmigration across the endothelium, functions as an immune suppressor molecule $(22,24,58,59)$. It activates plasma B cells and induces secretion of the B cell-derived peptide PEPITEM, which inhibits memory T cell migration (60).

In conclusion, the correlations between Acrp30, biological markers and severe CVID phenotypes indicate that Acrp30 plays a central role in the immune activation typical of this disease. Further studies are needed to clarify the molecular mechanisms underlying Acrp30 regulation and to decipher the biological role of this adipokine in the immune system.

\section{ETHICS STATEMENT}

The research protocol was approved by the Ethics Committee of the School of Medicine, University of Naples "Federico II" and was in accordance with the principles of the Helsinki II Declaration.

\section{AUTHOR CONTRIBUTIONS}

$\mathrm{AD}, \mathrm{GS}$, and AG substantially conceived the research and directed and discussed the comprehensive assembly of data acquisition, analysis, and interpretation; AP, IM, and ACM recruited, treated, and followed up CVID patients; FH recruited and treated CIDP patients; MC performed the statistical analysis; EN, RP, and MM did most of experimental work; EN and OS performed and coordinated the laboratory experimental and data acquisition ensuring that questions related to the accuracy or integrity of any part of the work are appropriately investigated and resolved; $\mathrm{AD}, \mathrm{GS}$, and $\mathrm{AG}$, with $\mathrm{AP}$ and $\mathrm{EN}$, wrote the manuscript and give the final approval for publication.

\section{ACKNOWLEDGMENTS}

The authors thank Jean Ann Gilder (Scientific Communication srl., Naples, Italy) for revising and editing the text.

\section{SUPPLEMENTARY MATERIAL}

The Supplementary Material for this article can be found online at http://journal.frontiersin.org/article/10.3389/fimmu.2017.00895/ full\#supplementary-material. 


\section{REFERENCES}

1. Cunningham-Rundles C. The many faces of common variable immunodeficiency. Hematology Am Soc Hematol Educ Program (2012) 2012:301-5. doi:10.1182/asheducation-2012.1.301

2. Chapel H, Lucas M, Lee M, Bjorkander J, Webster D, Grimbacher B, et al. Common variable immunodeficiency disorders: division into distinct clinical phenotypes. Blood (2008) 112(2):277-86. doi:10.1182/blood-2007-11-124545

3. Chapel H, Lucas M, Patel S, Lee M, Cunningham-Rundles C, Resnick E, et al. Confirmation and improvement of criteria for clinical phenotyping in common variable immunodeficiency disorders in replicate cohorts. J Allergy Clin Immunol (2012) 130(5):1197-8.e9. doi:10.1016/j.jaci.2012.05.046

4. Quinti I, Agostini C, Tabolli S, Brunetti G, Cinetto F, Pecoraro A, et al. Malignancies are the major cause of death in patients with adult onset common variable immunodeficiency. Blood (2012) 120(9):1953-4. doi:10.1182/ blood-2012-05-431064

5. Hel Z, Huijbregts RP, Xu J, Nechvatalova J, Vlkova M, Litzman J. Altered serum cytokine signature in common variable immunodeficiency. J Clin Immunol (2014) 34(8):971-8. doi:10.1007/s10875-014-0099-z

6. Vlkova M, Ticha O, Nechvatalova J, Kalina T, Litzman J, Mauri C, et al. Regulatory B cells in CVID patients fail to suppress multifunctional IFN- $\gamma+$ TNF- $\alpha+$ CD4+ T cells differentiation. Clin Immunol (2015) 160:292-300. doi:10.1016/j.clim.2015.06.013

7. Galic S, Oakhill JS, Steinberg GR. Adipose tissue as an endocrine organ. Mol Cell Endocrinol (2010) 316:129-39. doi:10.1016/j.mce.2009.08.018

8. Procaccini C, De Rosa V, Galgani M, Carbone F, La Rocca C, Formisano L, et al. Role of adipokines signaling in the modulation of $\mathrm{T}$ cells function. Front Immunol (2013) 4:332. doi:10.3389/fimmu.2013.00332

9. Wensveen FM, Valentić S, Šestan M, Wensveen TT, Polić B. Interactions between adipose tissue and the immune system in health and malnutrition. Semin Immunol (2015) 27(5):322-33. doi:10.1016/j.smim.2015.10.006

10. Exley MA, Hand L, O'Shea D, Lynch L. Interplay between the immune system and adipose tissue in obesity. J Endocrinol (2014) 223(2):R41-8. doi:10.1530/ JOE-13-0516

11. Nigro E, Scudiero O, Monaco ML, Palmieri A, Mazzarella G, Costagliola C, et al. New insight into adiponectin role in obesity and obesity-related diseases. Biomed Res Int (2014) 2014:658913. doi:10.1155/2014/658913

12. Kern PA, Di Gregorio GB, Lu T, Rassouli N, Ranganathan G. Adiponectin expression from human adipose tissue: relation to obesity, insulin resistance, and tumor necrosis factor-alpha expression. Diabetes (2003) 52:1779-85. doi:10.2337/diabetes.52.7.1779

13. Lacedonia D, Nigro E, Matera MG, Scudiero O, Monaco ML, Polito R, et al. Evaluation of adiponectin profile in Italian patients affected by obstructive sleep apnea syndrome. Pulm Pharmacol Ther (2016) 40:104-8. doi:10.1016/j. pupt.2016.07.008

14. Nigro E, Piombino P, Scudiero O, Monaco ML, Schettino P, Chambery A, et al. Evaluation of salivary adiponectin profile in obese patients. Peptides (2015) 63:150-5. doi:10.1016/j.peptides.2014.11.007

15. Nigro E, Daniele A, Scudiero O, Monaco ML, Roviezzo F, D’Agostino B, et al. Adiponectin in asthma: implications for phenotyping. Curr Protein Pept Sci (2015) 16:182-7. doi:10.2174/1389203716666150120095342

16. Costagliola C, Daniele A, Dell'Omo R, Romano MR, Aceto F, Agnifili L, et al. Aqueous humor levels of vascular endothelial growth factor and adiponectin in patients with type 2 diabetes before and after intravitreal bevacizumab injection. Exp Eye Res (2013) 110:50-4. doi:10.1016/j.exer.2013.02.004

17. Daniele A, De Rosa A, Nigro E, Scudiero O, Capasso M, Masullo M, et al. Adiponectin oligomerization state and adiponectin receptors airway expression in chronic obstructive pulmonary disease. Int J Biochem Cell Biol (2012) 44:563-9. doi:10.3390/nu5104115

18. Pang TT, Narendran P. The distribution of adiponectin receptors on human peripheral blood mononuclear cells. Ann N Y Acad Sci (2008) 1150:143-5. doi:10.1196/annals.1447.021

19. Gackowska L, Litwin M, Trojanek J, Eljaszewicz A, Kubiszewska I, Niemirska A, et al. Expression of adiponectin receptors on peripheral blood leukocytes of hypertensive children is associated with the severity of hypertension. Biomed Res Int (2015) 2015:742646. doi:10.1155/2015/742646

20. Chinetti G, Zawadski C, Fruchart JC, Staels B. Expression of adiponectin receptors in human macrophages and regulation by agonists of the nuclear receptors PPARalpha, PPARgamma, and LXR. Biochem Biophys Res Commun (2004) 314:151-8. doi:10.1016/j.bbrc.2003.12.058

21. Yamaguchi N, Argueta JG, Masuhiro Y, Kagishita M, Nonaka K, Saito T, et al. Adiponectin inhibits Toll-like receptor family-induced signaling. FEBS Lett (2005) 579:6821-6. doi:10.1016/j.febslet.2005.11.019

22. Yokota T, Oritani K, Takahashi I, Ishikawa J, Matsuyama A, Ouchi N, et al. Adiponectin, a new member of the family of soluble defense collagens, negatively regulates the growth of myelomonocytic progenitors and the functions of macrophages. Blood (2000) 96:1723-32.

23. Wulster-Radcliffe MC, Ajuwon KM, Wang J, Christian JA, Spurlock ME. Adiponectin differentially regulates cytokines in porcine macrophages. Biochem Biophys Res Commun (2004) 316:924-9. doi:10.1016/j.bbrc.2004.02.130

24. Kim KY, Kim JK, Han SH, Lim JS, Kim KI, Cho DH, et al. Adiponectin is a negative regulator of NK cell cytotoxicity. J Immunol (2006) 176:5958-64. doi:10.4049/jimmunol.176.10.5958

25. Tsao TS, Murrey HE, Hug C, Lee DH, Lodish HF. Oligomerization statedependent activation of NF-kappa B signaling pathway by adipocyte complement-related protein of $30 \mathrm{kDa}$ (Acrp30). J Biol Chem (2002) 277:29359-62. doi:10.1074/jbc.C200312200

26. Tomizawa A, Hattori Y, Kasai K. Induction of gene expression in response to globular adiponectin in vascular endothelial cells. Life Sci (2009) 85:457-61. doi:10.1016/j.lfs.2009.07.012

27. Ouchi N, Kihara S, Arita Y, Okamoto Y, Maeda K, Kuriyama H, et al. Adiponectin, an adipocyte-derived plasma protein, inhibits endothelial NF-kappaB signaling through a cAMP-dependent pathway. Circulation (2000) 102:1296-301. doi:10.1161/01.CIR.102.11.1296

28. Ajuwon KM, Spurlock ME. Adiponectin inhibits LPS-induced NF-kappaB activation and IL-6 production and increases PPARgamma2 expression in adipocytes. Am J Physiol Regul Integr Comp Physiol (2005) 288:R1220-5. doi:10.1152/ajpregu.00397.2004

29. Bruun JM, Lihn AS, Verdich C, Pedersen SB, Toubro S, Astrup A, et al. Regulation of adiponectin by adipose tissue-derived cytokines: in vivo and in vitro investigations in humans. Am J Physiol Endocrinol Metab (2003) 285:527-33. doi:10.1152/ajpendo.00110.2003

30. Robinson K, Prins J, Venkatesh B. Clinical review: adiponectin biology and its role in inflammation and critical illness. Crit Care (2011) 15:221. doi:10.1186/ cc10021

31. Tsatsanis C, Zacharioudaki V, Androulidaki A, Dermitzaki E, Charalampopoulos I, Minas V, et al. Adiponectin induces TNF-alpha and IL-6 in macrophages and promotes tolerance to itself and other pro-inflammatory stimuli. Biochem Biophys Res Commun (2005) 335:1254-63. doi:10.1016/j. bbrc.2005.07.197

32. Goldberg AC, Eliaschewitz FG, Montor WR, Baracho GV, Errante PR, Callero MA, et al. Exogenous leptin restores in vitro $\mathrm{T}$ cell proliferation and cytokine synthesis in patients with common variable immunodeficiency syndrome. Clin Immunol (2005) 114:147-53. doi:10.1016/j.clim.2004.09.002

33. Matarese G, Moschos S, Mantzoros CS. Leptin in immunology. J Immunol (2005) 174:3137-42. doi:10.4049/jimmunol.174.6.3137

34. Abella V, Scotece M, Conde J, Pino J, Gonzalez-Gay MA, Gómez-Reino JJ, et al. Leptin in the interplay of inflammation, metabolism and immune system disorders. Nat Rev Rheumatol (2017) 13(2):100-9. doi:10.1038/ nrrheum.2016.209

35. Fernández-Riejos P, Najib S, Santos-Alvarez J, Martín-Romero C, Pérez-Pérez A, González-Yanes C, et al. Role of leptin in the activation of immune cells. Mediators Inflamm (2010) 2010:568343. doi:10.1155/2010/568343

36. Daniele A, Cammarata R, Masullo M, Nerone N, Finamore F, D’Andrea M, et al. Analysis of adiponectin gene and comparison of its expression in two different pig breeds. Obesity (2008) 16:1869-74. doi:10.1038/oby.2008.275

37. Vlková M, Fronková E, Kanderová V, Janda A, Ruzicková S, Litzman J, et al. Characterization of lymphocyte subsets in patients with common variable immunodeficiency reveals subsets of naive human B cells marked by CD24 expression. J Immunol (2010) 185:6431-8. doi:10.4049/jimmunol.0903876

38. Kalina T, Stuchlý J, Janda A, Hrusák O, Růzicková S, Sedivá A, et al. Profiling of polychromatic flow cytometry data on B-cells reveals patients' clusters in common variable immunodeficiency. Cytometry (2009) 75:902-9. doi:10.1002/ cyto.a.20801

39. Barbosa RR, Silva SP, Silva SL, Tendeiro R, Melo AC, Pedro E, et al. Monocyte activation is a feature of common variable immunodeficiency irrespective 
of plasma lipopolysaccharide levels. Clin Exp Immunol (2012) 169:263-72. doi:10.1111/j.1365-2249.2012.04620.x

40. Quinti I, Soresina A, Guerra A, Rondelli R, Spadaro G, Agostini C, et al. Effectiveness of immunoglobulin replacement therapy on clinical outcome in patients with primary antibody deficiencies: results from a multicenter prospective cohort study. J Clin Immunol (2011) 31:315-22. doi:10.1007/ s10875-011-9511-0

41. Graziano V, Pecoraro A, Mormile I, Quaremba G, Genovese A, Buccelli C, et al. Delay in diagnosis affects the clinical outcome in a cohort of CVID patients with marked reduction of IgA serum levels. Clin Immunol (2017) 180:1-4. doi:10.1016/j.clim.2017.03.011

42. Khokher MA, Janah S, Dandona P. Human immunoglobulin G stimulates human adipocyte lipogenesis. Diabetologia (1983) 25:264-8. doi:10.1007/ BF00279941

43. Palming J, Gabrielsson BG, Jennische E, Smith U, Carlsson B, Carlsson LM. Plasma cells and Fc receptors in human adipose tissue - lipogenic and antiinflammatory effects of immunoglobulins on adipocytes. Biochem Biophys Res Commun (2006) 343:43-8. doi:10.1016/j.bbrc.2006.02.114

44. Resnick ES, Moshier EL, Godbold JH, Cunningham-Rundles C. Morbidity and mortality in common variable immune deficiency over 4 decades. Blood (2012) 119(7):1650-7. doi:10.1182/blood-2011-09-377945

45. Horn J, Manguiat A, Berglund LJ, Knerr V, Tahami F, Grimbacher B, et al. Decrease in phenotypic regulatory T cells in subsets of patients with common variable immunodeficiency. Clin Exp Immunol (2009) 156(3):446-54. doi:10.1111/j.1365-2249.2009.03913.x

46. Arumugakani G, Wood PM, Carter CR. Frequency of Treg cells is reduced in CVID patients with autoimmunity and splenomegaly and is associated with expanded CD21lo B lymphocytes. J Clin Immunol (2010) 30(2):292-300. doi:10.1007/s10875-009-9351-3

47. Yu GP, Chiang D, Song SJ, Hoyte EG, Huang J, Vanishsarn C, et al. Regulatory $\mathrm{T}$ cell dysfunction in subjects with common variable immunodeficiency complicated by autoimmune disease. Clin Immunol (2009) 131(2):240-53. doi:10.1016/j.clim.2008.12.006

48. Agarwal S, Smereka P, Harpaz N, Cunningham-Rundles C, Mayer L. Characterization of immunologic defects in patients with common variable immunodeficiency (CVID) with intestinal disease. Inflamm Bowel Dis (2011) 17(1):251-9. doi:10.1002/ibd.21376

49. Fantuzzi G. Adiponectin in inflammatory and immune-mediated diseases. Cytokine (2013) 64:1-10. doi:10.1016/j.cyto.2013.06.317

50. Otero M, Lago R, Gomez R, Lago F, Dieguez C, Gómez-Reino JJ, et al. Changes in plasma levels of fat-derived hormones adiponectin, leptin, resistin and visfatin in patients with rheumatoid arthritis. Ann Rheum Dis (2006) 65:1198-201. doi:10.1136/ard.2005.046540

51. Sada KE, Yamasaki Y, Maruyama M, Sugiyama H, Yamamura M, Maeshima Y, et al. Altered levels of adipocytokines in association with insulin resistance in patients with systemic lupus erythematosus. J Rheumatol (2006) 33:1545-52.
52. Yamamoto K, Kiyohara T, Murayama Y, Kihara SN, Okamoto Y, Funahashi T, et al. Production of adiponectin, an anti-inflammatory protein, in mesenteric adipose tissue in Crohn's disease. Gut (2005) 54:789-96. doi:10.1136/gut.2004.046516

53. Nigro E, Scudiero O, Sarnataro D, Mazzarella G, Sofia M, Bianco A, et al. Adiponectin affects lung epithelial A549 cell viability counteracting TNF $\alpha$ and IL-1ß toxicity through AdipoR1. Int J Biochem Cell Biol (2013) 45:1145-53. doi:10.1016/j.biocel.2013.03.003

54. Kumada M, Kihara S, Ouchi N, Kobayashi H, Okamoto Y, Ohashi K, et al. Adiponectin specifically increased tissue inhibitor of metalloproteinase-1 through interleukin-10 expression in human macrophages. Circulation (2004) 109:2046-9. doi:10.1161/01.CIR.0000127953.98131.ED

55. Lappas M, Permezel M, Rice GE. Leptin and adiponectin stimulate the release of proinflammatory cytokines and prostaglandins from human placenta and maternal adipose tissue via nuclear factor-kappaB, peroxisomal proliferator-activated receptor-gamma and extracellularly regulated kinase $1 / 2$ Endocrinology (2005) 146:3334-42.

56. Xu A, Wang Y, Keshaw H, Xu LY, Lam KS, Cooper GJ. The fat-derived hormone adiponectin alleviates alcoholic and nonalcoholic fatty liver diseases in mice. J Clin Invest (2003) 112:91-100. doi:10.1172/JCI200317797

57. Maeda N, Shimomura I, Kishida K, Nishizawa H, Matsuda M, Nagaretani H, et al. Diet-induced insulin resistance in mice lacking adiponectin/ACRP30. Nat Med (2002) 8:731-7. doi:10.1038/nm724

58. Mandal P, Pratt BT, Barnes M, McMullen MR, Nagy LE. Molecular mechanism for adiponectin-dependent M2 macrophage polarization: link between the metabolic and innate immune activity of full-length adiponectin. J Biol Chem (2011) 286:13460-9. doi:10.1074/jbc.M110.204644

59. Chimen M, McGettrick HM, Apta B, Kuravi SJ, Yates CM, Kennedy A, et al. Homeostatic regulation of $\mathrm{T}$ cell trafficking by a B cell-derived peptide is impaired in autoimmune and chronic inflammatory disease. Nat Med (2015) 21(5):467-75. doi:10.1038/nm.3842

60. Ohashi K, Parker JL, Ouchi N, Higuchi A, Vita JA, Gokce N, et al. Adiponectin promotes macrophage polarization toward an anti-inflammatory phenotype. J Biol Chem (2010) 285(9):6153-60. doi:10.1074/jbc.M109.088708

Conflict of Interest Statement: The authors declare that the research was conducted in the absence of any commercial or financial relationships that could be construed as a potential conflict of interest.

Copyright $\odot 2017$ Pecoraro, Nigro, Polito, Monaco, Scudiero, Mormile, Cesoni Marcelli, Capasso, Habetswallner, Genovese, Daniele and Spadaro. This is an open-access article distributed under the terms of the Creative Commons Attribution License (CC BY). The use, distribution or reproduction in other forums is permitted, provided the original author(s) or licensor are credited and that the original publication in this journal is cited, in accordance with accepted academic practice. No use, distribution or reproduction is permitted which does not comply with these terms. 